\title{
PREDICTION OF MAXIMUM POSSIBLE STORM SURGES IN ISE BAY UNDER A FUTURE CLIMATE
}

\author{
Tomokazu Murakami ${ }^{1}$, Jun Yoshino ${ }^{2}$ and Takashi Yasuda ${ }^{3}$
}

\begin{abstract}
This study aims at investigating space and time-distributions of possible maximum storm surges in Ise Bay caused by potential typhoons based on the SRES A1B scenario. Initial fields of 50 potential typhoons were provided by using potential vorticity bogussing scheme of a tropical cyclone. Then, the distributions over the whole area of Ise Bay under the 50 initial fields were predicted by using an atmosphere-ocean-wave coupled model. The results show that all storm tides in Nagoya Port caused by the 50 potential typhoons exceed $3.5 \mathrm{~m}$ which is the largest storm tide ever recorded in Japan and that its maximum value reaches $6.9 \mathrm{~m}$.
\end{abstract}

Keywords: storm surge, typhoon, future climate, Ise Bay, numerical simulation

\section{INTRODUCTION}

Recently, the importance of Ise Bay, Japan, has increased because many important industries and trading ports are located in Ise Bay. However, Ise Bay has a history of the worst storm surge disaster in Japan. Typhoon Vera (designated as the Ise Bay typhoon in Japan) struck Ise Bay in September 1959, generating the largest storm tides ever recorded in Japan. A storm tide of $3.5 \mathrm{~m}$ was observed at Nagoya Port, located in the innermost part of Ise Bay, causing the deaths of 4,000 or more people. Consequently, the design sea level in Ise Bay was set to $3.5 \mathrm{~m}$ based on that storm surge. The embankments around Ise Bay were constructed under this standard, and safety against storm surge disasters has been maintained until today.

According to IPCC 4AR, global warming are expected to increase typhoon, hurricane, and cyclone intensities. Therefore, an important concern is that a storm surge that exceeds storm tide of $3.5 \mathrm{~m}$ might occur in Ise Bay under a future climate. Elucidations of spatial and temporal distributions of the possible maximum values of storm surge in Ise Bay under future climate conditions are necessary to produce effective countermeasures against storm surges.

Conventional simulations for elucidations of maximum possible storm surges have used parametric typhoon models (Mitsuta and Fujii, 1987) such as those presented by Schloemer (1954) and others, and ocean models such as POM (Mellor, 2004) using a sigma coordinate system. However, the parametric typhoon models are inadequate for physical evaluation of the roughness effects of complicated coastlines and landforms and three-dimensional effects of the meteorological field on the sea surface winds. Furthermore, for prediction of typhoons under a future climate, the parametric typhoon models cannot evaluate the intensity and tracks of the typhoons according to physical laws governing the atmosphere and ocean because best track data (observed data) of typhoons are nonexistent. Conventional ocean models using the sigma coordinate system suffer from an important problem (Murakami et al., 2008): The accuracy of the vertical finite-difference scheme depends on the water depth. This shortcoming results from the increased error of the vertical finite-difference scheme offshore because the vertical grid spacing described by the sigma coordinate system corresponds to the water depth, which increases the error of the inflow rates of seawater from offshore. Because the storm surges occurring in the inner bay are strongly influenced by inflow rates of seawater from offshore, ocean models incorporating the sigma coordinate system cannot calculate storm surges with high accuracy.

To resolve the problems posed by conventional simulations, we develop a numerical simulation system incorporating an atmosphere-ocean-wave coupled model and a typhoon potential vorticity bogussing scheme. The spatial and temporal distributions of the possible maximum values of storm surge in Ise Bay under the future climate are elucidated using the numerical simulation system. The climate in September 2099, as inferred from the SRES A1B scenario, is assumed as the future meteorological condition affected by global warming. Under this condition, the typhoon potential vorticity bogussing scheme presents the initial fields including 50 cases of the maximum potential

\footnotetext{
${ }^{1}$ Storm, Flood, and Landslide Research Department, National Research Institute for Earth Science and Disaster Prevention, 3-1, Tennodai, Tsukuba, Ibaraki, 305-0006, Japan

2 Environmental and Renewable Energy Systems Division, Graduate School of Engineering, Gifu University, 1-1 Yanagido, Gifu, 501-1193, Japan

${ }^{3}$ Aichi University of Technology, 50-2 Manori Nishihasama-cho, Gamagori, Aichi, 443-0047, Japan
} 
typhoons striking Ise Bay. Then, the spatial and temporal distributions of the storm surges and high waves in Ise Bay, in addition to the strong winds and heavy rainfall around Ise Bay under the 50 initial fields are predicted using the atmosphere-ocean-wave coupled model.

\section{CALCULATION METHOD}

(1) Calculation domain: Ise Bay

In this study, the storm surges caused by the maximum possible typhoons under the future climate are predicted in Ise Bay, Japan (Fig. 1).

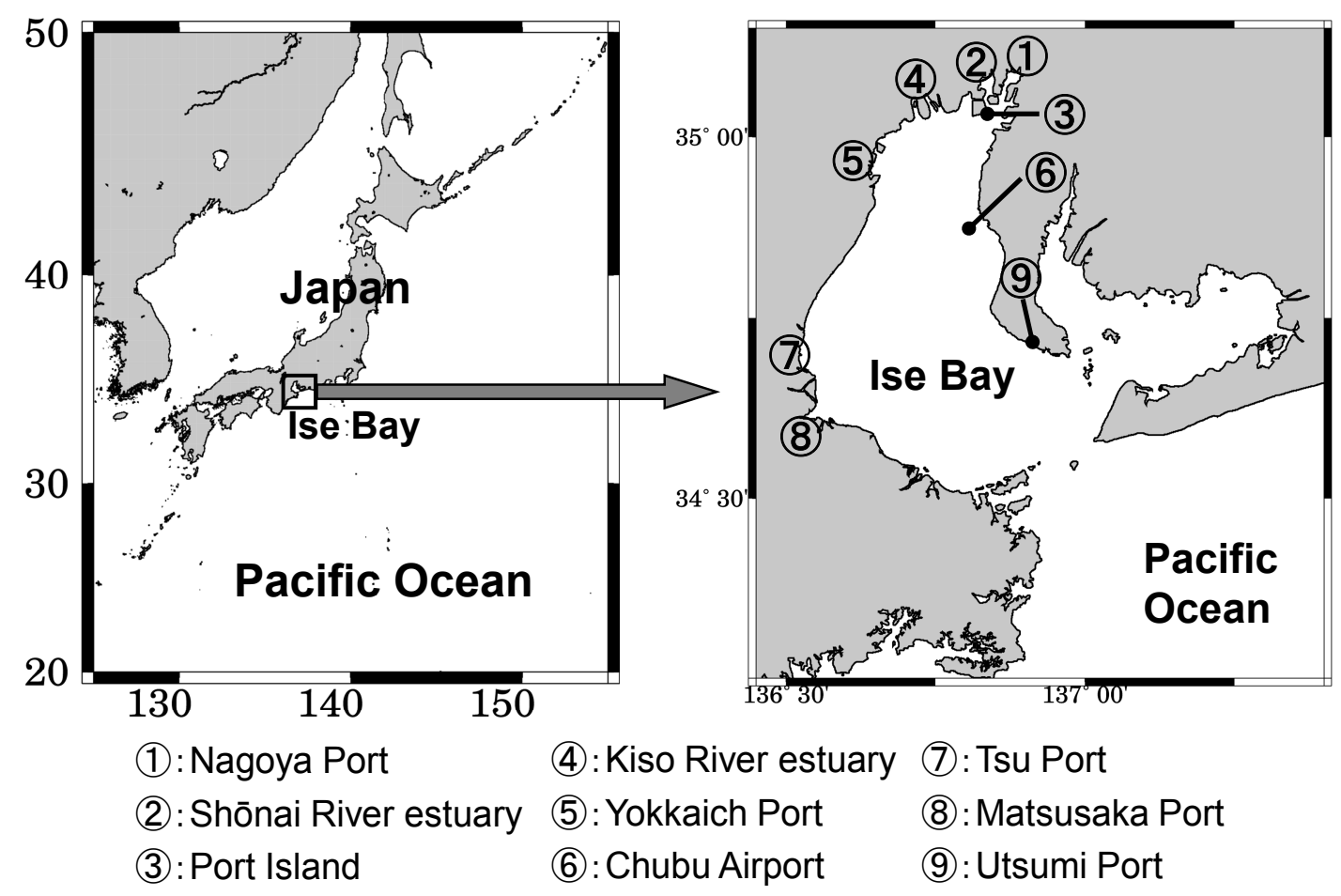

Figure 1. Ise Bay and nine main points.

\section{(2) Typhoon potential vorticity bogussing scheme}

The typhoon potential vorticity bogussing scheme developed by Yoshino et al. (2011) is used to provide the initial fields of the MM5. This scheme treats the meteorological field as a potential vorticity field, and divides it into a mean field changing in a long period and a deviation field changing in a short period. The influence of global warming is reflected not only in the central pressure and internal dynamic structure around the typhoon, but also in the typhoon environment by adding the temperature variation of global warming to the former mean field of the potential vorticity field. Because the latter deviation field of the potential vorticity field includes effects of the subtropical highpressure belt and mid-latitude trough, this scheme can provide an initial field that makes the typhoon strike the targeted areas by moving the deviation field.

The scenario assumed in this study is the following: (1) The climate in September of 2099 based on the SRES A1B scenario is assumed as the future meteorological condition. (2) The typhoon reaches the maximum intensity under the thermodynamic condition. (3) 50 typhoons are assumed to strike Ise Bay with different courses. Then, the following treatments are performed in the typhoon potential vorticity bogussing scheme.

i). The potential vorticity field based on ECMWF/ERA40 reanalysis data in September, 1959 is divisible into a mean field and a deviation field.

ii). The atmospheric and sea surface temperature of SRES A1B scenario in September, 2099 are added to the mean field.

iii). The 50 possible maximum typhoons are set in the initial field on section of $26.5^{\circ} \mathrm{N}, 131.35-$ $135.70^{\circ} \mathrm{E}$ at intervals of $9 \mathrm{~km}$. 


\section{(3) Atmosphere-ocean-wave coupled model}

The atmosphere-ocean-wave coupled model which is used to calculate the strong winds, heavy rainfall, storm surges, and high waves is constructed using the meteorological model MM5, the ocean model CCM, and the wave model SWAN. Figure 2 portrays a calculation diagram of the coupled model.

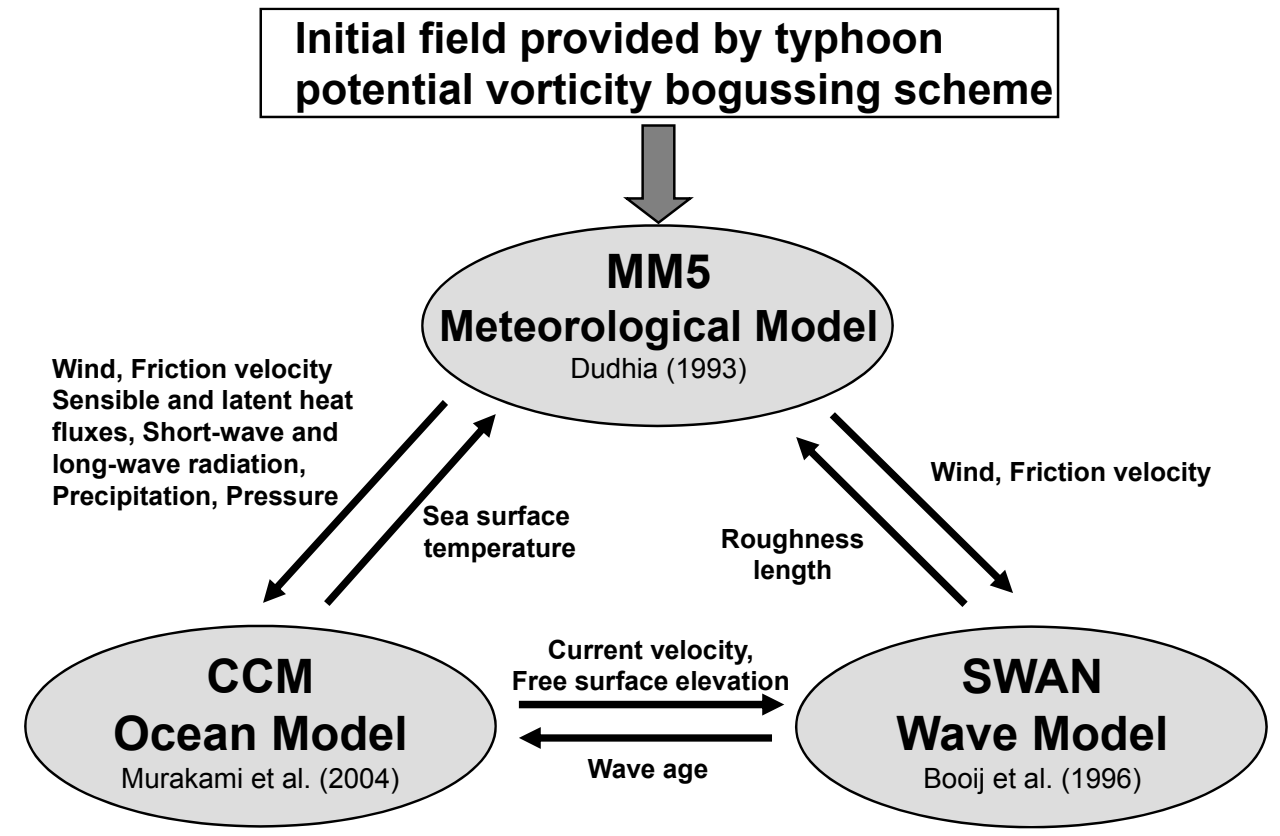

Figure 2. Schematic diagram of the atmosphere-ocean-wave coupled model.

In fact, MM5 (Dudhia, 1993) is a non-hydrostatic, fully compressible primitive equation model designed to simulate complex mesoscale meteorological phenomena of approximately a few to several hundred kilometers. It can therefore be used to evaluate the effects of physical roughness of a complicated coastline and landform, the three-dimensional effects of the meteorological field on the sea surface winds, and so on. The initial fields provided by the typhoon potential vorticity bogussing scheme described above are applied to the MM5 constituting the coupled model.

The Coastal ocean Current Model (CCM) is characterized by adoption of the multi-sigma coordinate system developed by Murakami et al. (2004), although it is a primitive ocean model. The multi-sigma coordinate system divides the calculation domain into many regions in the vertical direction and applies the conventional sigma coordinate into each divided region. The multi-sigma coordinate system is defined as presented in Figure 3. Here, the divided regions are respectively designated as regions I, II, and III from the sea surface. In addition, SI is the distance from the sea surface to the boundary between region I and region II, and SII is the distance from the sea surface to the boundary between region II and region III. Regions III or more are similarly defined. There, $\mathrm{h}$ is the total water depth, and hi is the water depth in region I; its maximum value equals SI, hII in the region II and its maximum equals SII - SI, and hIII in the region III and its maximum equal SIII - SII. In addition, $\zeta$ denotes the free surface elevation from the averaged sea surface level. Figure 4 depicts layouts of grid-points defined by the multi-sigma coordinate system and those by the conventional sigma coordinate system in Ise Bay. The relation between the vertical grid-spacing in the Eulerian coordinate system and the vertical grid-spacing $\Delta z$ in the conventional sigma coordinate system is defined as $\Delta z=\Delta \sigma \cdot h$. Figure 4(b) shows that the value of $\Delta z$ becomes remarkably large offshore and induces a large error of the vertical finite-difference scheme in the offshore area affected by strong winds. Results show that the inflow rates of seawater from offshore cannot be calculated accurately as long as a conventional sigma coordinate is used. In contrast, the value of $\Delta z$ immediately below the averaged sea surface in the multi-sigma coordinate system is independent of the water depth; it can always maintain a high resolution, as presented in Figure 4(a). This feature enables highly accurate calculation of the vertical differencing scheme immediately below the mean sea surface, which is 
crucial for correct evaluation of the influence of the sea surface winds, together with a correct description of the submarine topography.

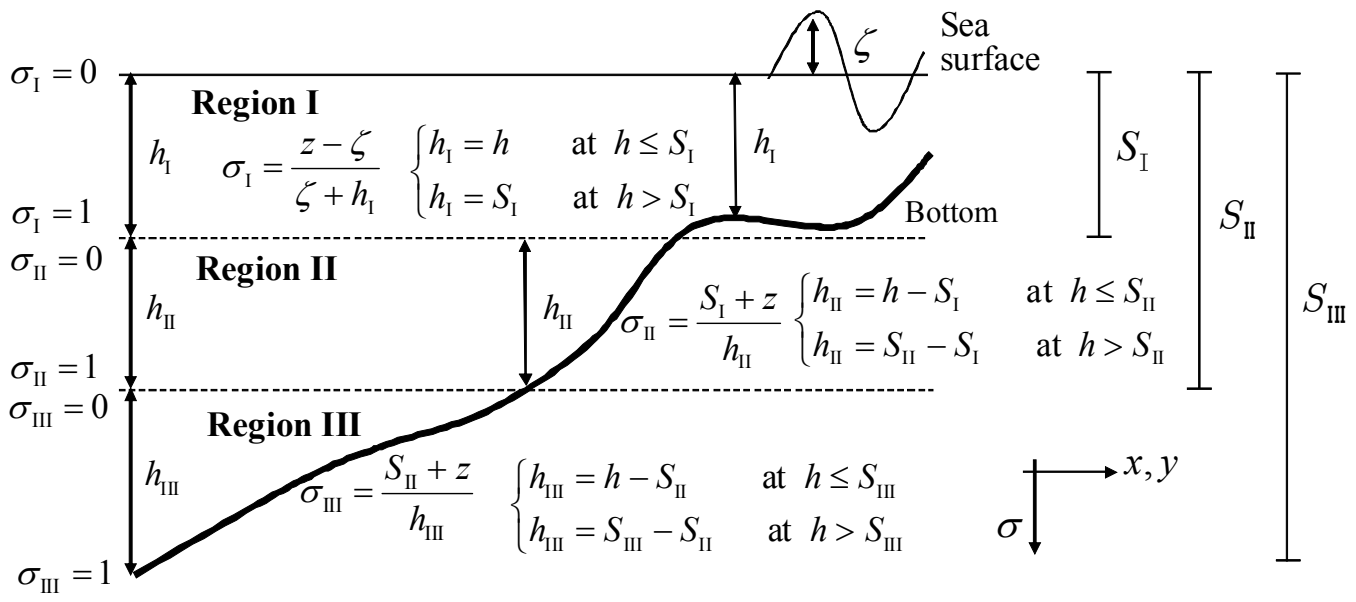

Figure 3. Definition of the multi-sigma coordinate system.

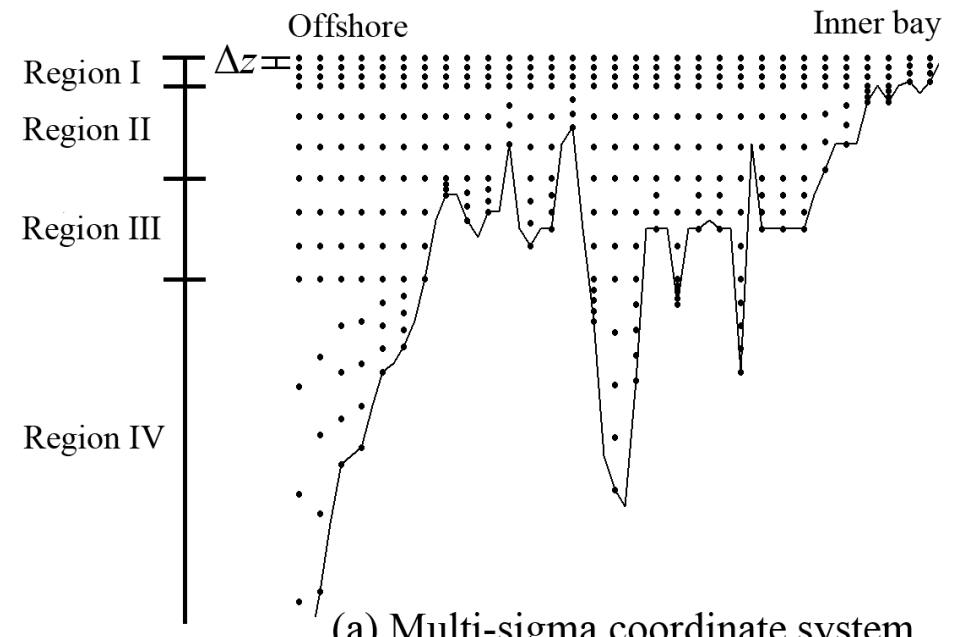

(a) Multi-sigma coordinate system

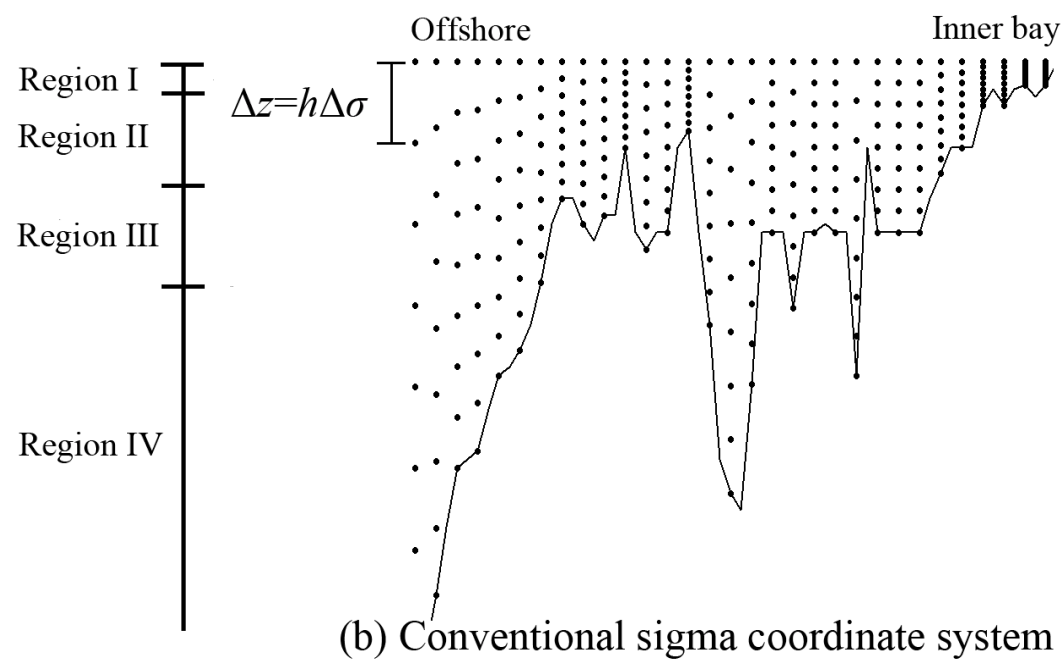

Figure 4. Layouts of grid points using the multi-sigma coordinate system and the conventional sigma coordinate system in Ise Bay. Black points mark the grid points.. 
SWAN (Booij et al., 1996) is a sophisticated third-generation time-dependent spectral wave model designed for the near-shore to offshore zone. It can simulate wave generation and propagation as affected by local winds.

Calculations of the strong winds, heavy rainfall, storm surges, and high waves in and around Ise Bay under the 50 initial fields using the coupled model are performed based on the configuration presented in Table 1.

\begin{tabular}{|c|c|c|}
\hline \multicolumn{3}{|c|}{ Table 1. Model configuration } \\
\hline Coupled model & $\begin{array}{l}\text { Time interval of data } \\
\text { exchange }\end{array}$ & $300 \mathrm{~s}$ \\
\hline \multirow{6}{*}{$\begin{array}{l}\text { Meteorological } \\
\text { model (MM5) }\end{array}$} & $\begin{array}{l}\text { Calculation domain } \\
\text { (two-way nesting) }\end{array}$ & $\begin{array}{l}\text { Region 1: } 23.6-39.6^{\circ} \mathrm{N}, 127.0-143.9^{\circ} \mathrm{E} \\
\text { Region 2: } 33.9-35.2^{\circ} \mathrm{N}, 136.0-137.6^{\circ} \mathrm{E}\end{array}$ \\
\hline & Horizontal resolution & Region 1: $9 \mathrm{~km}$ Region 2: $3 \mathrm{~km}$ \\
\hline & Number of horizontal grids & Region 1: $199 \times 160$ Region 2: $52 \times 52$ \\
\hline & Vertical levels & Region 1: 23 Region 2: 23 \\
\hline & Time step & Region 1: $30 \mathrm{~s}$ Region 2: $10 \mathrm{~s}$ \\
\hline & Physical parameterizations & $\begin{array}{l}\text { Planetary boundary layer: Blackadar scheme } \\
\text { Cloud physics: Reisner graupel scheme }\end{array}$ \\
\hline \multirow{6}{*}{$\begin{array}{l}\text { Ocean model } \\
\qquad(\mathrm{CCM})\end{array}$} & Calculation domain & $34.2-35.1^{\circ} \mathrm{N}, 136.5-137.4^{\circ} \mathrm{E}$ \\
\hline & Horizontal resolution & $450 \mathrm{~m}$ \\
\hline & Number of horizontal grids & $209 \times 208$ \\
\hline & $\begin{array}{l}\text { Number of regions in multi- } \\
\text { sigma }\end{array}$ & 7 \\
\hline & Total number of layers & 31 \\
\hline & Time step & $2 \mathrm{~s}$ \\
\hline \multirow{3}{*}{$\begin{array}{l}\text { Wave model } \\
\text { (SWAN) }\end{array}$} & $\begin{array}{l}\text { Calculation domain } \\
\text { (one-way nesting) }\end{array}$ & $\begin{array}{l}\text { Region } 1: 28.2-35.2^{\circ} \mathrm{N}, 135.0-139.0^{\circ} \mathrm{E} \\
\text { Region } 2: 33.2-35.1^{\circ} \mathrm{N}, 135.3-138.4^{\circ} \mathrm{E} \\
\text { Region } 3: 34.2-35.1^{\circ} \mathrm{N}, 136.5-137.4^{\circ} \mathrm{E}\end{array}$ \\
\hline & Number of horizontal grids & $\begin{array}{l}\text { Region 1: } 300 \times 523 \text { Region 2: } 300 \times 192 \\
\text { Region 3: } 209 \times 208\end{array}$ \\
\hline & Time step & $150 \mathrm{~s}$ \\
\hline
\end{tabular}

\section{RESULTS AND DISCUSSION}

Figure 5 depicts the tracks of 50 potential typhoons calculated using the coupled model. Figure 6 depicts the time evolutions of their central pressures. As presented in Fig. 5, 50 potential typhoons pass over a wide range from Ise Bay to Lake Biwa. This variation engenders different time evolutions of the central pressures, as presented in Fig. 6, because the sea surface temperature, land topography, and other factors strongly influence typhoon intensities. The influences of the sea surface temperature and land topography on the typhoon intensity cannot be evaluated physically using the previously described parametric typhoon models because the models require observed data of the typhoon tracks and central pressures as input data. However, the numerical simulation system developed here enables us to evaluate the influences of the sea surface temperature and land topography physically without 
such observed data. The central pressures of 50 potential typhoons at the onset of their landing vary from $895 \mathrm{hPa}$ to $905 \mathrm{hPa}$, falling well below the $930 \mathrm{hPa}$ of observed central pressure of typhoon Vera, which generated the largest storm tides ever recorded in Japan
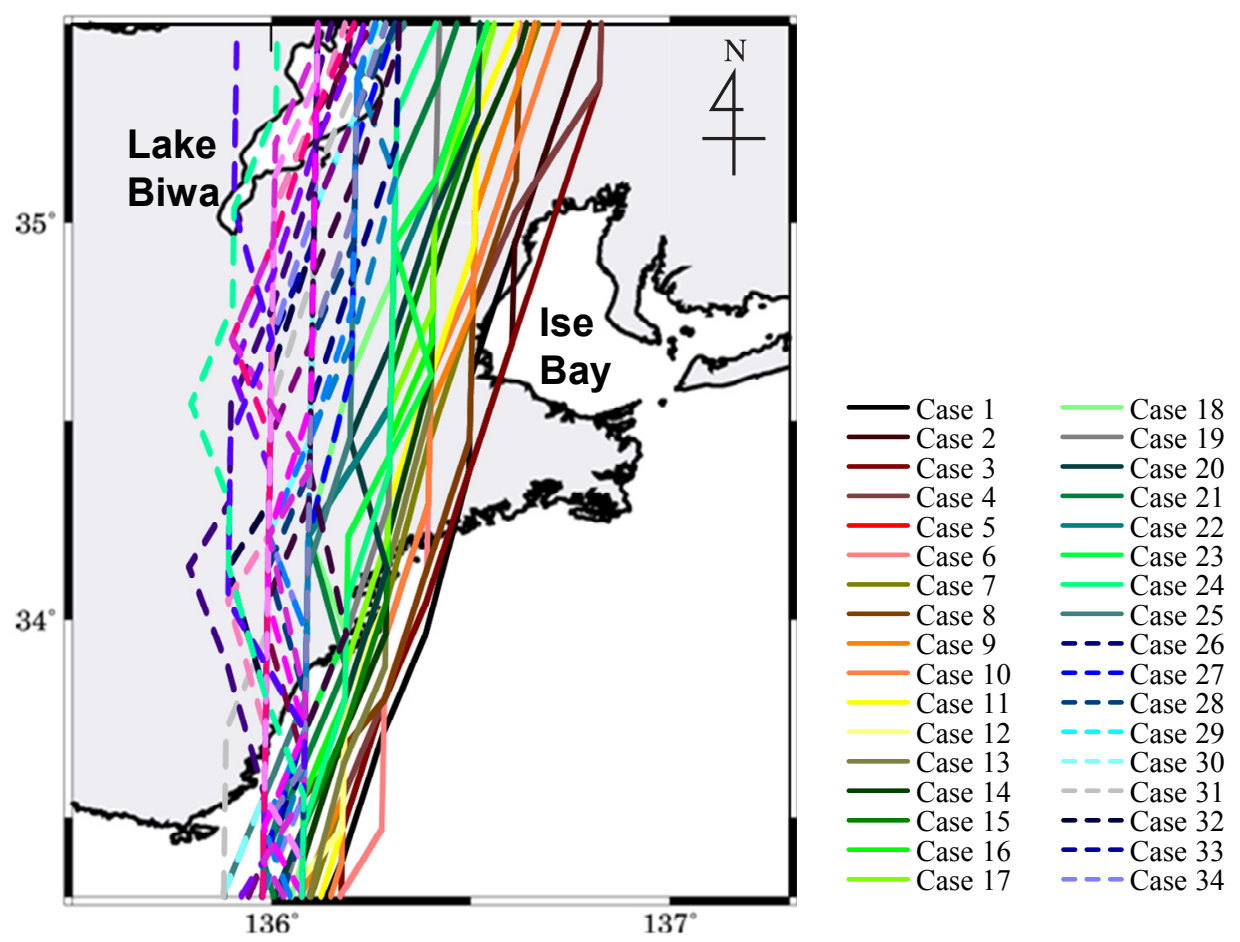

Figure 5 . Tracks of 50 potential typhoons.

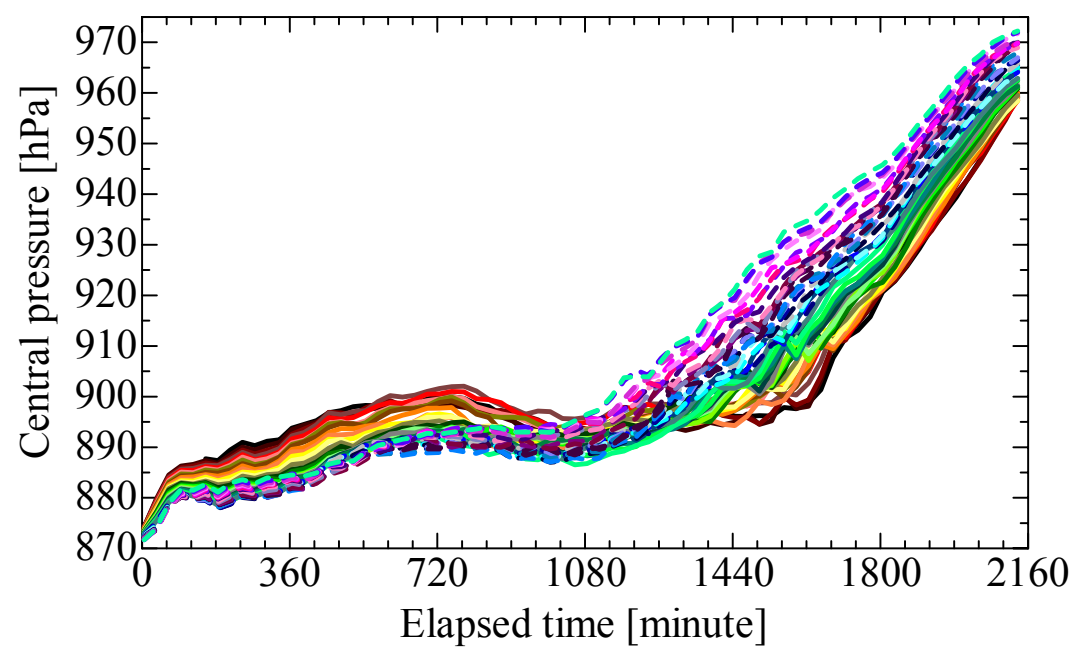

Figure 6. Time evolutions of central pressures of 50 potential typhoons.

Figure 7 presents distributions of the maximum value of storm tides, significant wave heights, wind speeds, and amounts of rainfall generated by 50 potential typhoons at each location. As described above, the largest storm tide ever recorded in Japan was $3.5 \mathrm{~m}$. The design sea level has been set to 3.5 $\mathrm{m}$ based on that storm surge. Our predictions for the storm tides show that the maximum storm tides exceed $3.5 \mathrm{~m}$ height over a large area from the center to the inner part of Ise Bay. If the mean monthly highest water level of $1.22 \mathrm{~m}$ is added to this storm tide, then the sea level exceeds the design sea level of embankments around Ise Bay. Moreover, the significant wave height in the center area of Ise Bay 
exceeds $8 \mathrm{~m}$. Even that of Nagoya Port surrounded by complicated landforms (refer to Fig. 1) reaches approximately $1.5 \mathrm{~m}$. As shown in Fig. 7(c), strong winds exceeding $45 \mathrm{~m} / \mathrm{s}$ blow throughout the whole Ise Bay area. Winds around Yokkaichi Port and Chubu Airport are particularly strong, with values reaching $50 \mathrm{~m} / \mathrm{s}$. High storm tides and significant wave height like those presented in Figs. 7(a) and 7 (b) were generated by these strong winds. In addition, heavy rainfall exceeding $150 \mathrm{~mm} / 36 \mathrm{~h}$ is predicted throughout the entire Ise Bay area, as presented in Fig. 7(d).

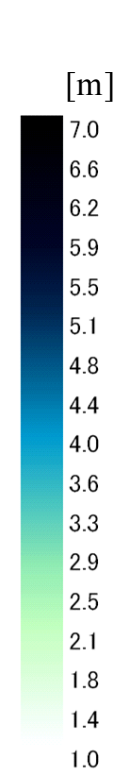

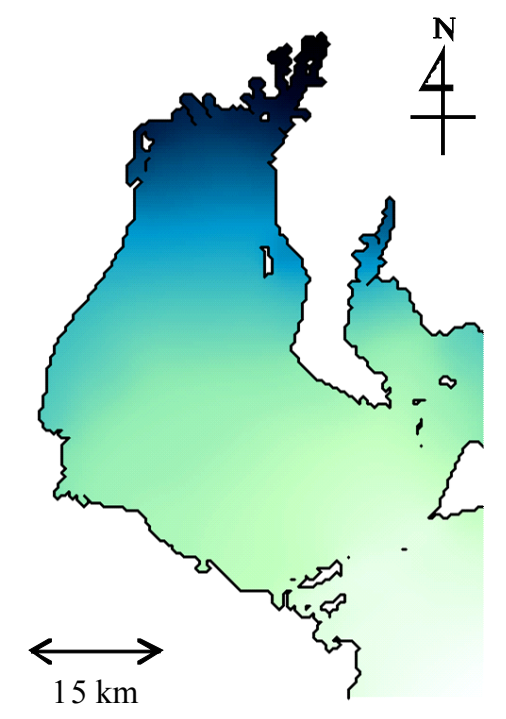

(a) Storm tide

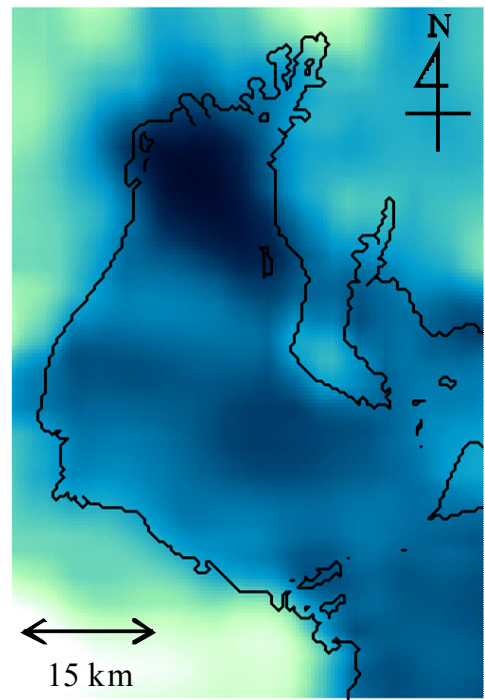

(c) Wind speed

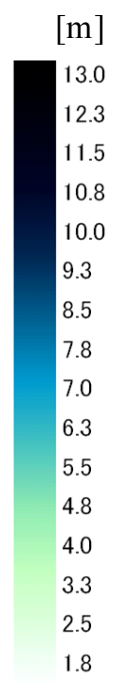

1.0

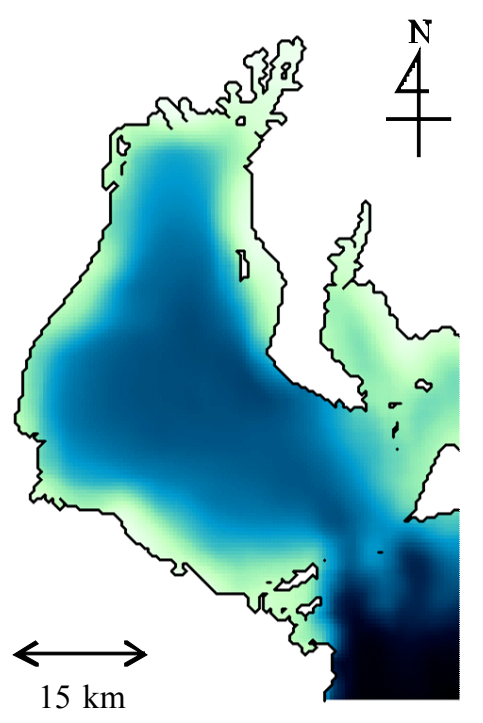

(b) Significant wave height

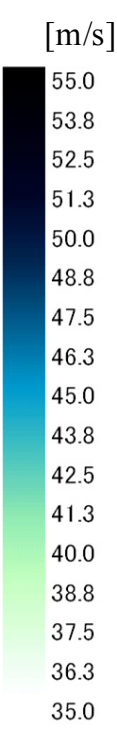

Figure 7. Distributions of the maximum value of storm tides, significant wave heights, wind speed and amount of rainfall generated by 50 potential typhoons at each location.

Figures 8, 9, 10 and 11 present maximum values of the storm tides, significant wave heights, wind speeds and amount of rainfalls of each case at nine main points (refer to Fig. 1), in addition to their averaged values. As shown in Fig. 8, results show that the maximum values in inner part from Yokkaichi Port exceed $5 \mathrm{~m}$ height. The storm tide at Nagoya Port located in the innermost part is the highest of Ise Bay. Its value is $6.9 \mathrm{~m}$. The storm tide of $6.9 \mathrm{~m}$ results from strong winds of $45 \mathrm{~m} / \mathrm{s}$ or higher velocity as depicted in Fig. 10 and remarkably exceeds the largest storm tide of $3.5 \mathrm{~m}$ ever 
recorded in Japan. The maximum values of the significant wave height, the wind speed and the amount of rainfall are, respectively, $6.1 \mathrm{~m}$ at Chubu Airport, $51 \mathrm{~m} / \mathrm{s}$ at Yokkaichi Port and $228 \mathrm{~mm} / 36 \mathrm{~h}$ at Utsumi Port.

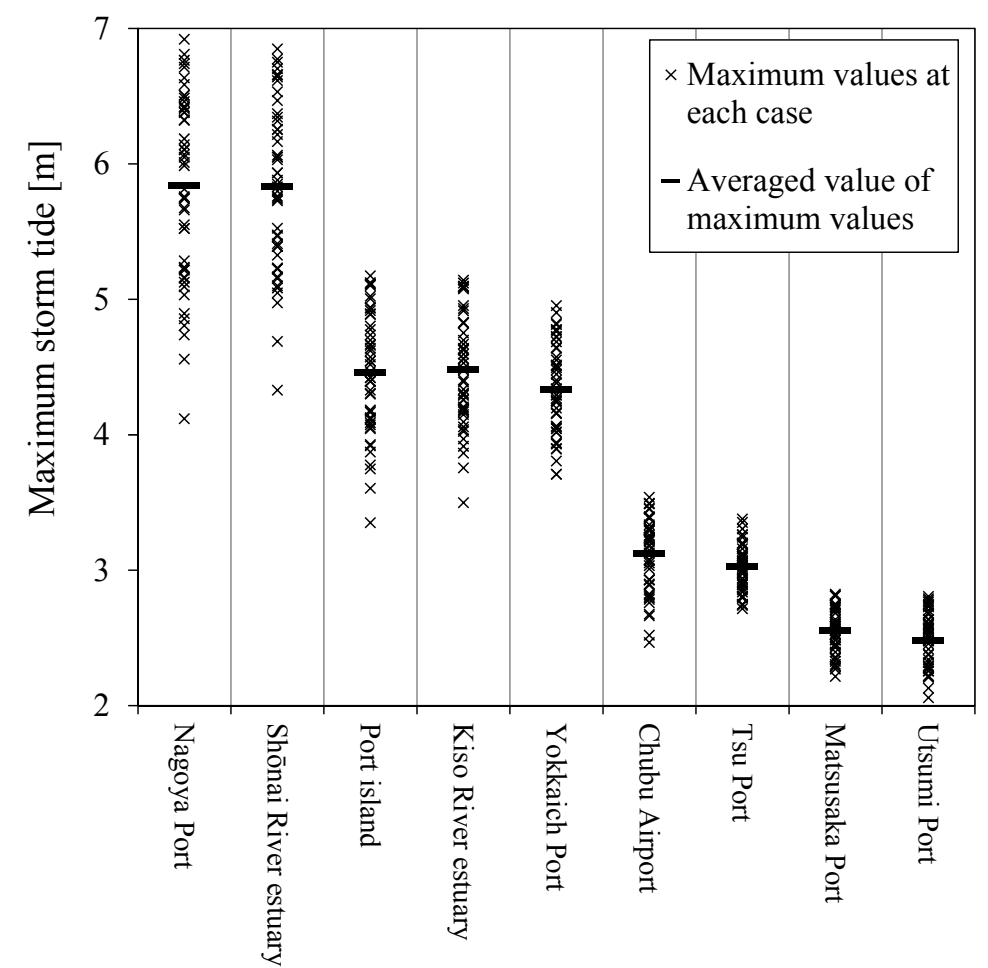

Figure 8. Maximum values of storm tides of each case at nine main points (refer to Fig. 1), and their averaged values.

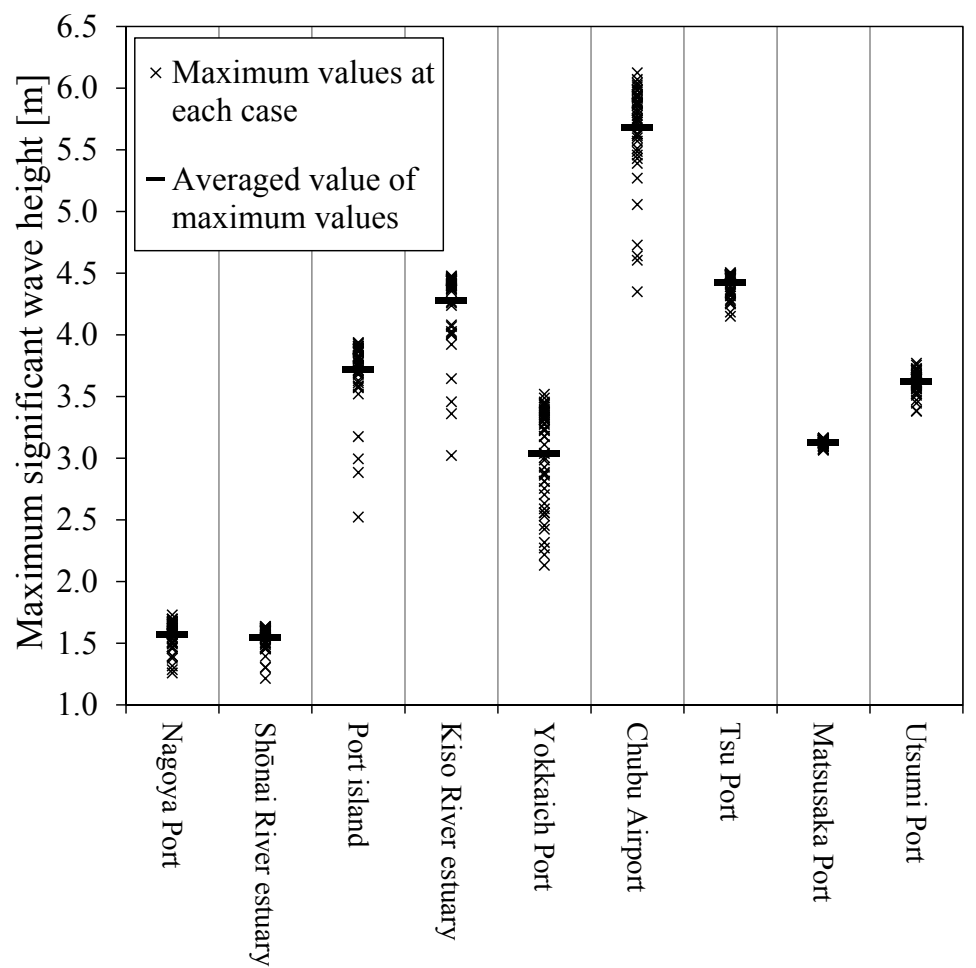

Figure 9. Maximum values of significant wave heights of each case at nine main points (refer to Fig. 1), and their averaged values. 


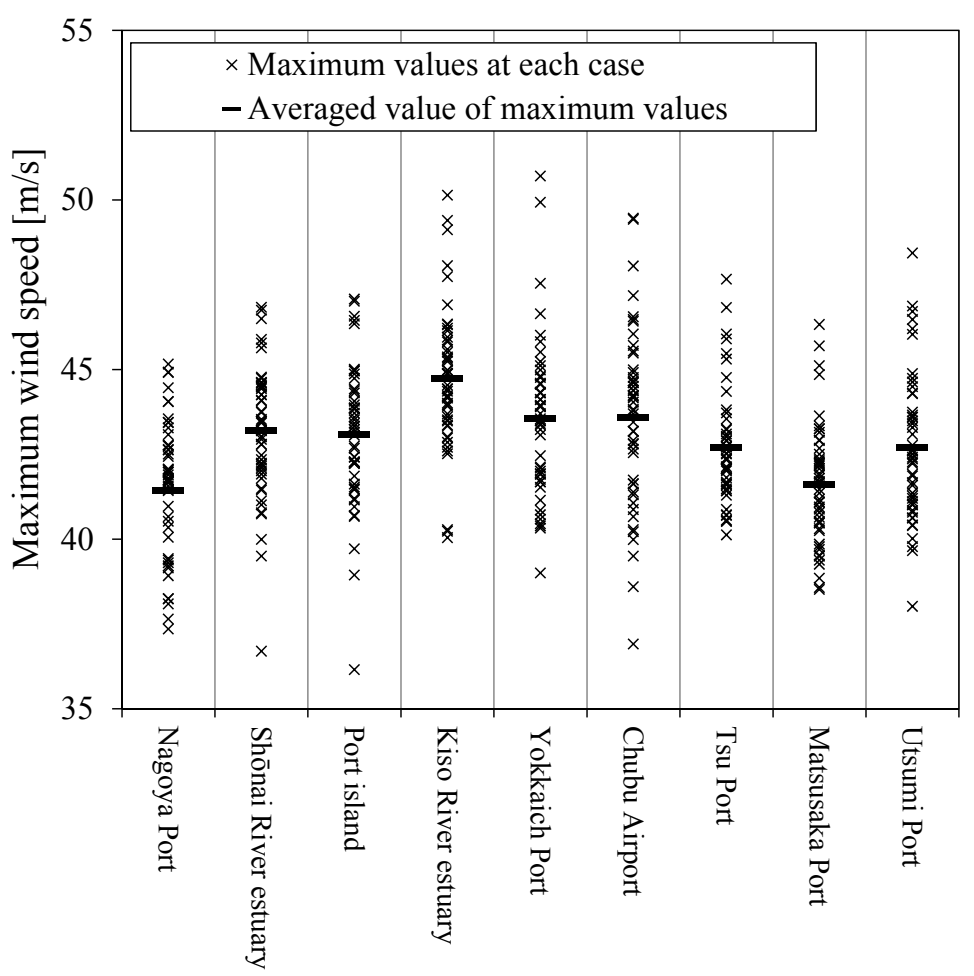

Figure 10. Maximum values of wind speeds of each case at nine main points (refer to Fig. 1), and their averaged values.

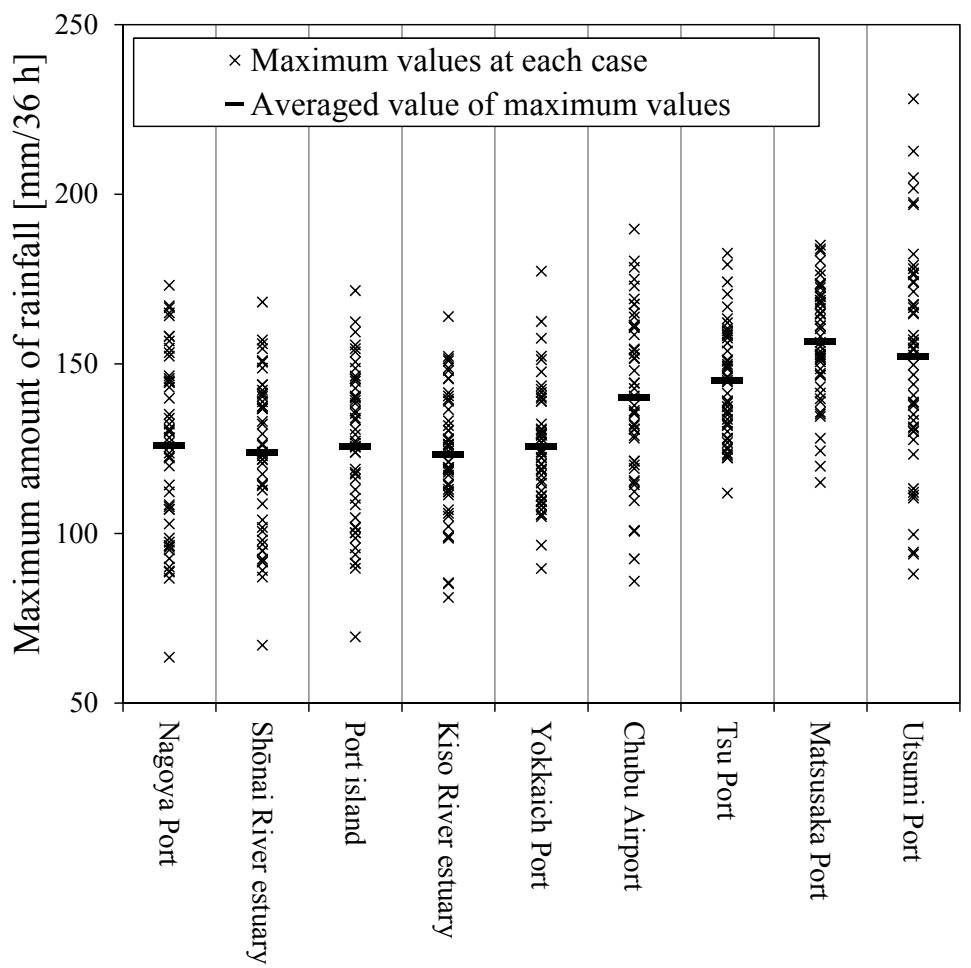

Figure 11. Maximum values of amounts of rainfall of each case at nine main points (refer to Fig. 1), and their averaged values. 
Figures 12, 13, 14 and 15 present time evolutions of the storm tides, significant wave heights, wind speeds and amounts of rainfall at Nagoya Port, Kiso River estuary, Yokkaichi Port and Chubu Airport (refer to Fig. 1). The figures shown here are generated by the potential typhoon exciting the maximum storm tide at each location. Results show that the time differences among the peak times of storm tide, significant wave height, wind speed, and the amount of rainfall at Nagoya Port, Kiso River estuary, Yokkaichi Port and Chubu Airport are, respectively, $110 \mathrm{~min}, 80 \mathrm{~min}, 50 \mathrm{~min}$ and $80 \mathrm{~min}$. The peak times of external forces caused by the maximum potential typhoon gather in a short time range. Therefore, the possibility exists of an occurrence of the coupled hazard in Ise Bay.

Figure 16 shows times exceeding the design values for the storm tide at 9 main points (refer to Fig. 1). The longest time exceeding the design storm tide is $170 \mathrm{~min}$ at Tsu Port (design storm tide $2.14 \mathrm{~m}$ ), which is 86 min longer than the time of Nagoya Port (design storm tide $3.55 \mathrm{~m}$ ) in which the highest storm tide 6.9 m occurred.

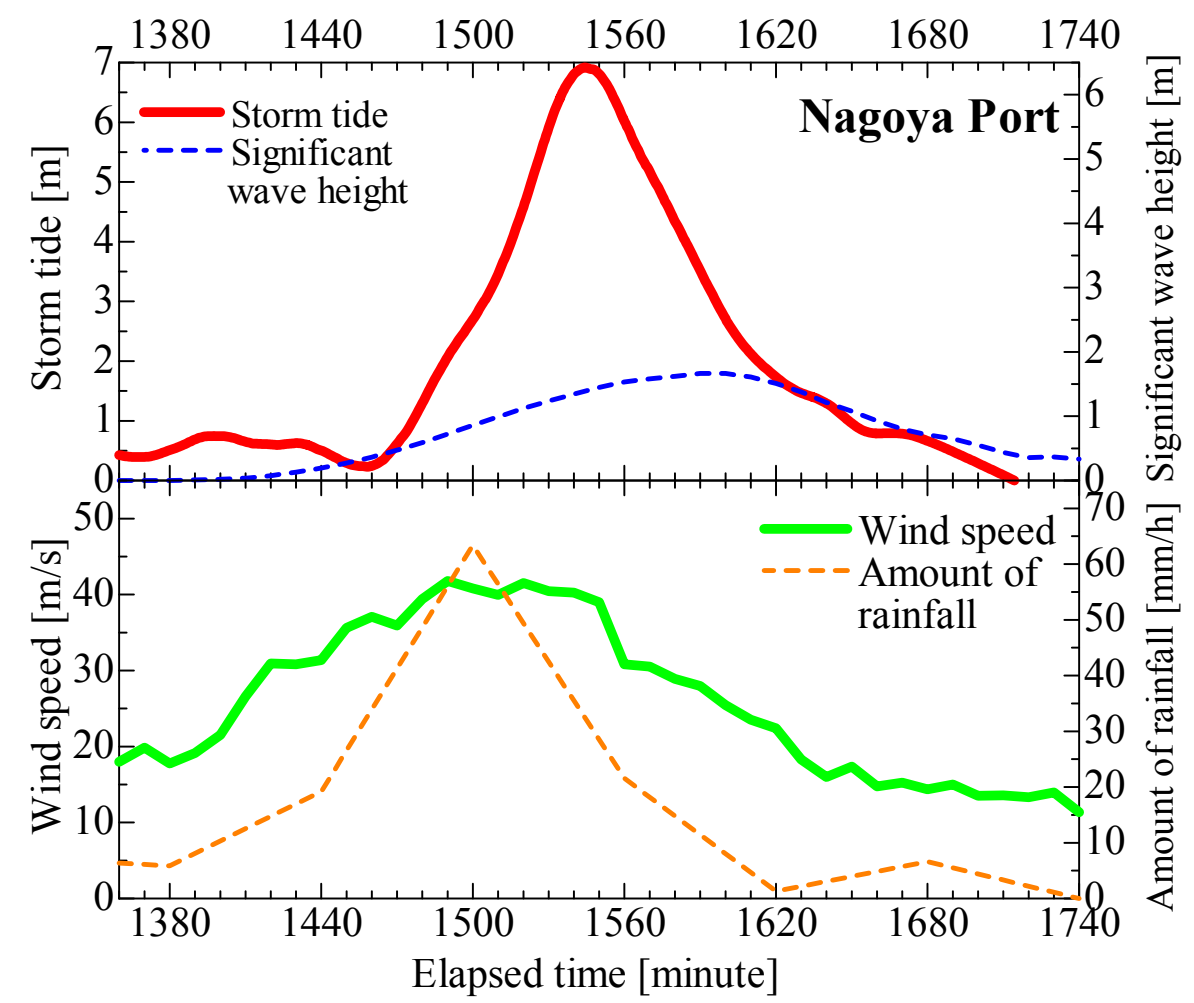

Figure 12. Time evolutions of the storm tides, significant wave heights, wind speeds, and the amount of rainfall at Nagoya Port (refer to Fig. 1). 


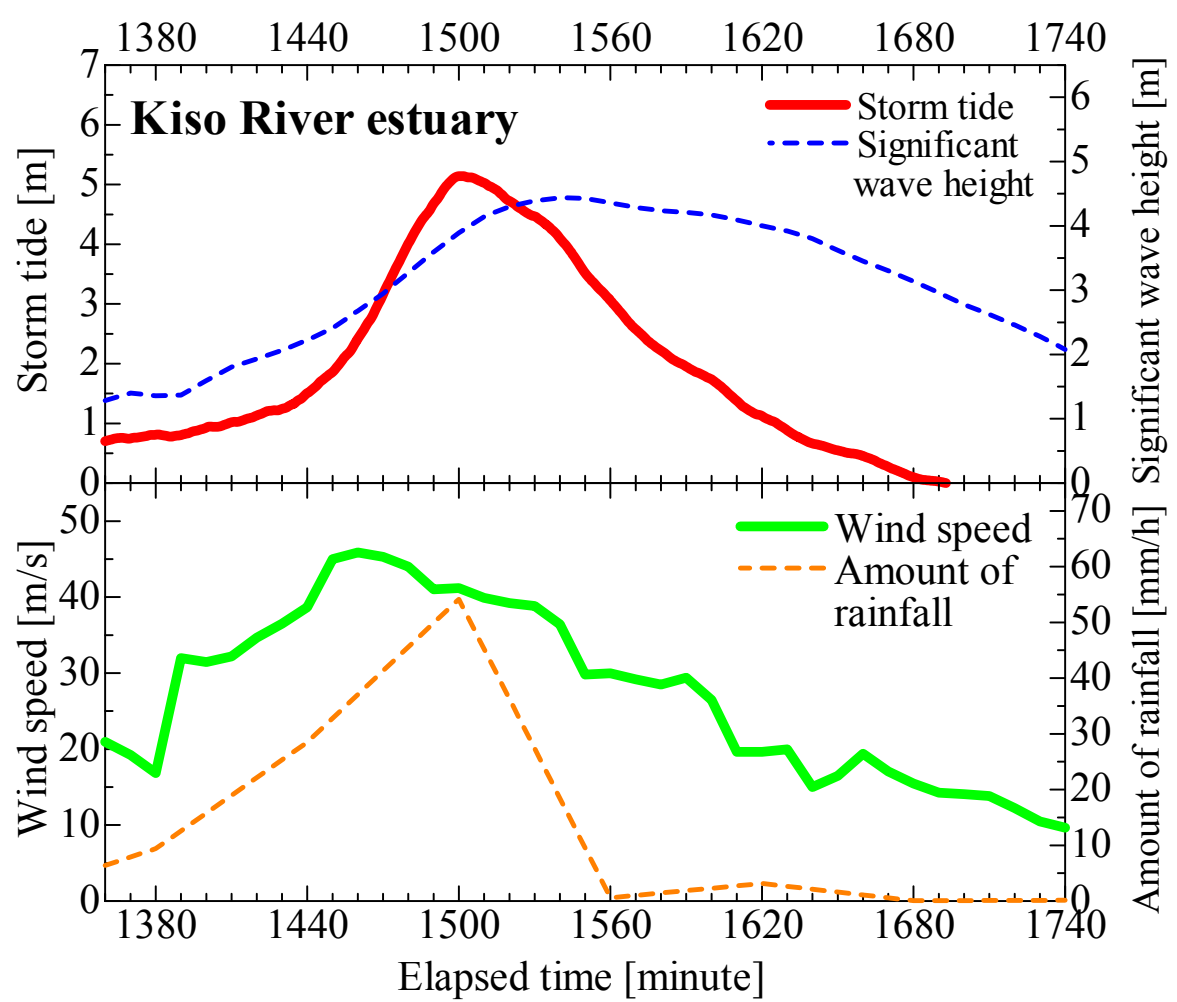

Figure 13. Time evolutions of the storm tides, significant wave heights, wind speeds, and the amount of rainfall at Kiso River estuary (refer to Fig. 1).

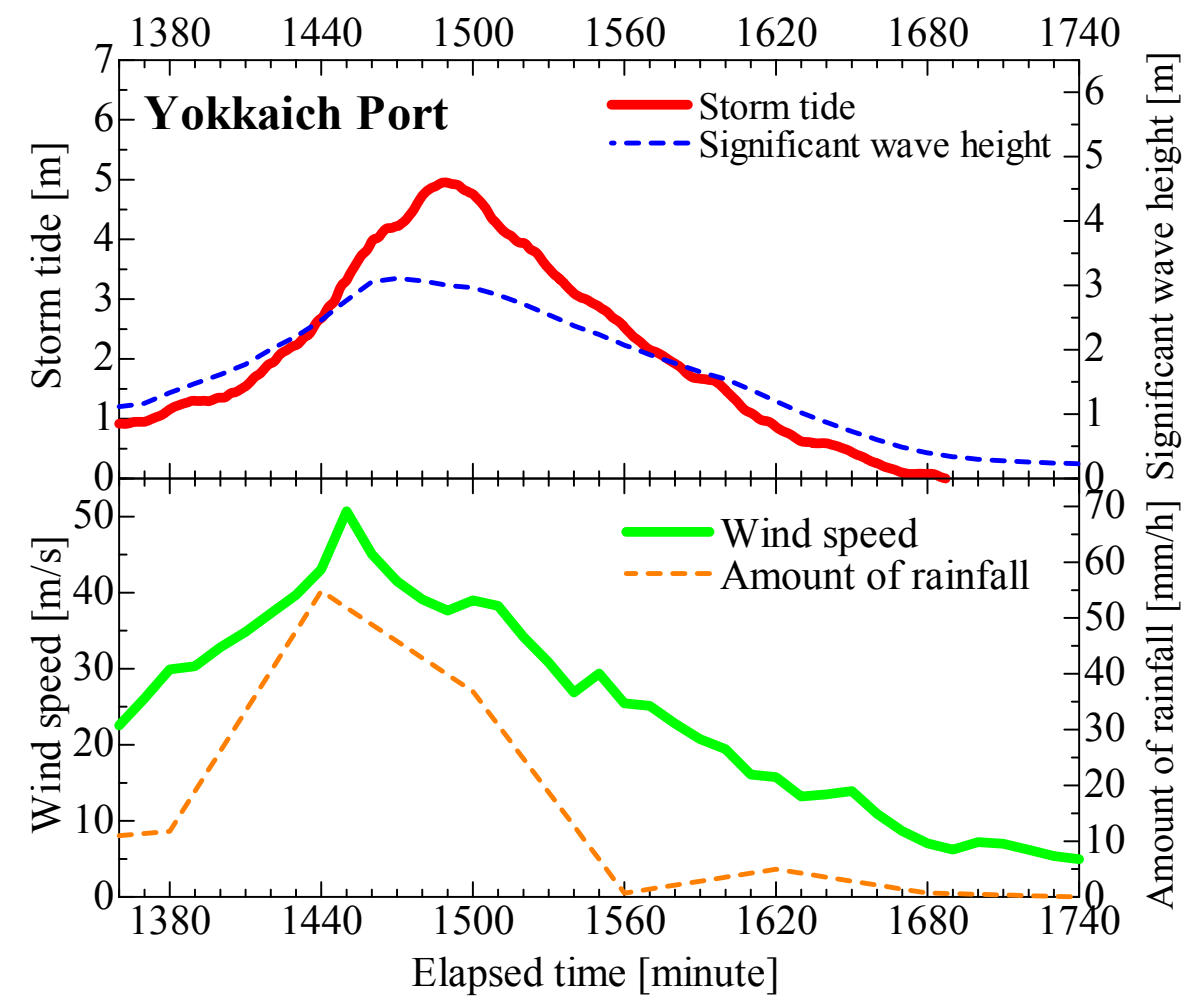

Figure 14. Time evolutions of the storm tides, significant wave heights, wind speeds, and the amount of rainfall at Yokkaichi Port (refer to Fig. 1). 


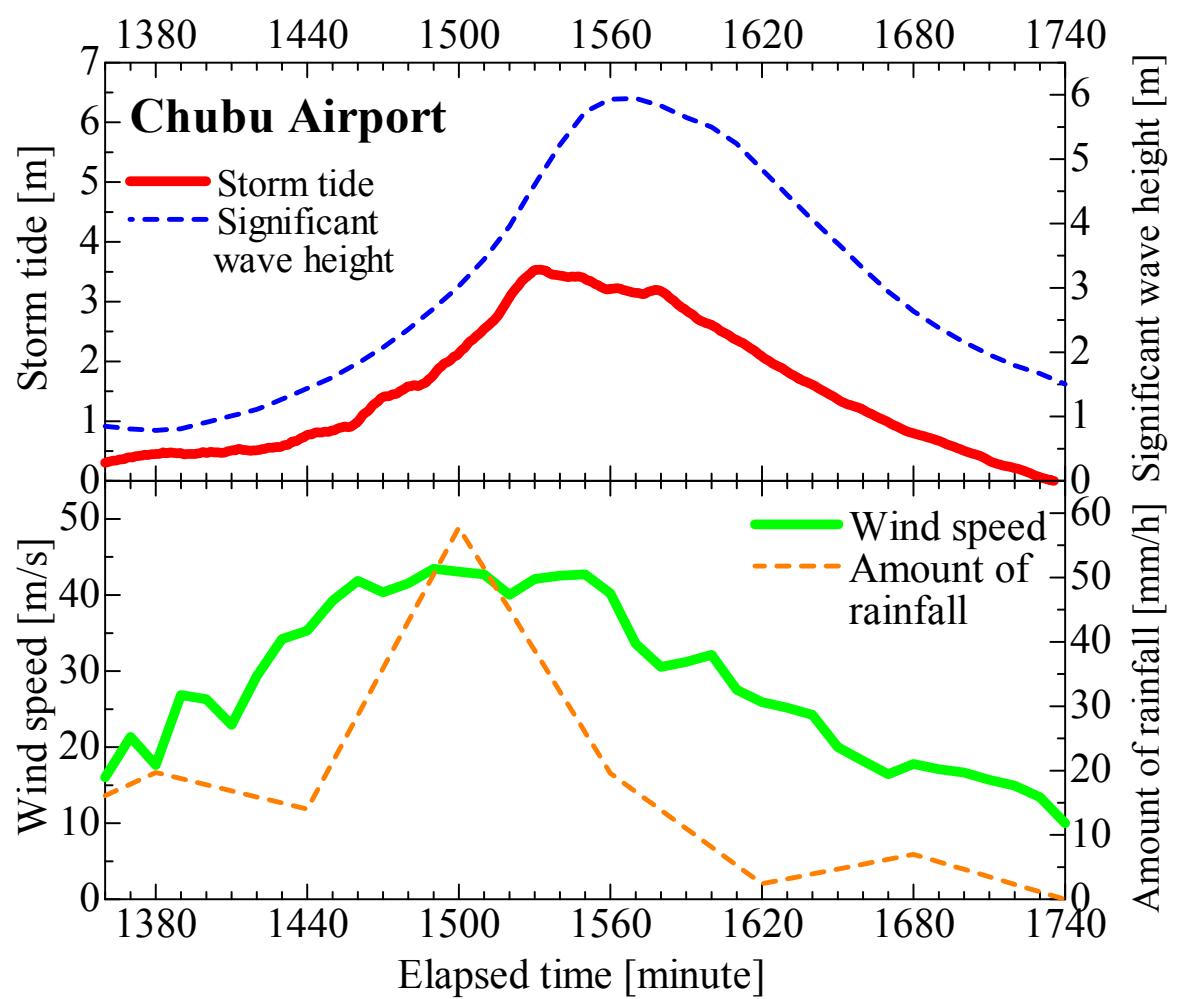

Figure 15. Time evolutions of the storm tides, significant wave heights, wind speeds, and the amount of rainfall at Chubu Airport (refer to Fig. 1).

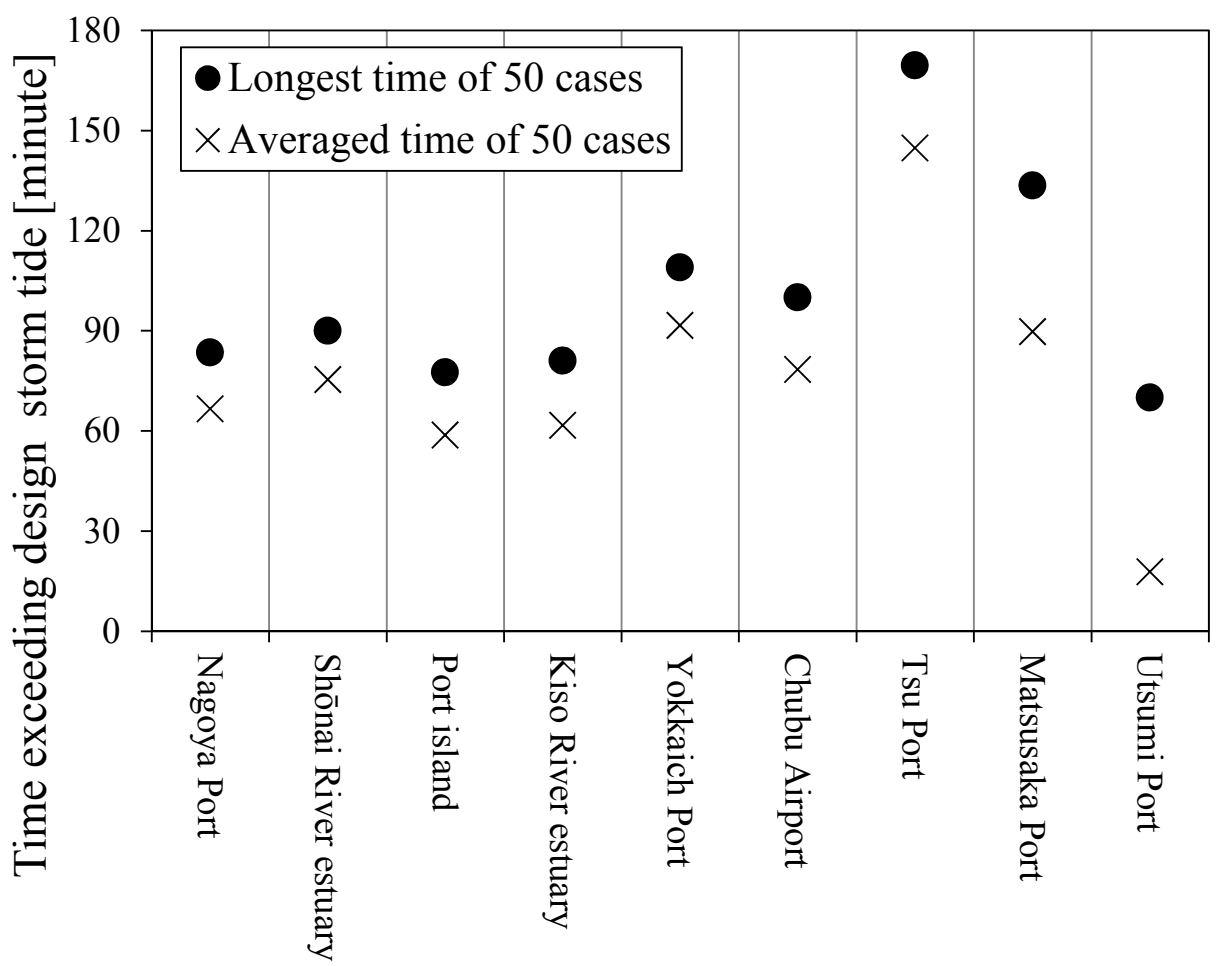

Figure 16. Times exceeding design values for the storm tide at nine main points (refer to Fig. 1). 


\section{CONCLUSION}

For this study, we developed a numerical simulation system to calculate the storm surges created by the maximum potential typhoons in a future climate. The spatial and temporal distributions of the possible maximum values of storm surge in Ise Bay, Japan, under the future climate were evaluated using this simulation system. Primary results obtained in this study are summarized as follows.

- We developed a numerical simulation system incorporating the atmosphere-ocean-wave coupled model and the typhoon potential vorticity bogussing scheme.

- This numerical simulation system can make the typhoon strike the targeted areas based on physical laws. Moreover, this system enables accurate calculation of all the storm surges and high waves generated by typhoons.

- Results of calculation in Ise Bay on September 2099 demonstrated the possibility of occurrence of a 6.9-m storm tide at Nagoya Port. This storm tide height remarkably exceeds the largest storm tide ever recorded in Japan, which is $3.5 \mathrm{~m}$. If the mean monthly highest water level of $1.22 \mathrm{~m}$ is added to this storm tide, then the sea level exceeds the design sea level of embankments around Ise Bay. Therefore, the possibility exists of the occurrence of the large storm surge disaster in Ise Bay under the future climate.

- The peak times of storm tide, significant wave height, wind speed and amount of rainfall gather in a short time range. Therefore, the possibility exists of the occurrence of the coupled hazard in Ise Bay.

\section{ACKNOWLEDGMENTS}

This research was supported by a Grant-in-Aid for Scientific Research 24360199 from JSPS and the National Research Institute for Earth Science and Disaster Prevention through a research project.

\section{REFERENCES}

Booij, N., Holthuijsen, L.H., and R.C. Ris. 1996. The SWAN wave model for shallow water, Proc. 25th Int. Conf. Coastal Engng., 1, 668-676.

Dudhia, J. 1993. A nonhydrostatic version of the Penn State-NCAR mesoscale model: Validation test and simulation of an Atlantic cyclone and cold front, Mon. Wea. Rev., 121, 1493-1513.

Schloemer, R.W. 1954. Analysis and synthesis of hurricane wind patterns over Lake Okeechobee, Florida, Hydrometeorological Report, 31, 1-49.

Mitsuta, Y., and Fujii, T.(1987. Analysis and synthesis of typhoon wind pattern over Japan, Bull. Disaster Prevention Research Institute, 37, 169-185.

Mellor, G.L. 2004. Users guide for a three-dimensional, primitive equation, numerical ocean model, http://www.aos.princeton.edu/WWWPUBLIC/htdocs.pom, 56 pp.

Murakami, T., Y. Yasuda, and T. Ohsawa. 2004. Development of a multi-sigma coordinate model coupled with an atmospheric model for the calculation of coastal currents, Ann. J. Coastal Eng., 51, JSCE, 366-370 (in Japanese).

Murakami, T., Yoshino, J., and Yasuda, T. 2008. A New Simulation Model of Storm Surges in Inland Sea Affected by Inflow from Offshore and Complicated Winds, Proc. of the 31st Int. Conf. on Coastal Engineering, 1147-1159.

Yoshino, J., Iwamoto, S., Murakami, T. and Yasuda, T. 2011. Dynamic estimation of the maximum potential wind speed in the Bay of Tokyo based on the typhoon potential vorticity bogussing system, Journal of Japan Society of Civil Engineers B2 (Coastal Engineering), 67, 411-415 (in Japanese). 